\title{
STRUCTURE AND PHYSICAL-CHEMICAL PROPERTIES OF HUMIC ACIDS OF OLIGOTROPHIC PEAT BOG OF ARKHANGELSK REGION
}

\author{
IRINA KUZNETSOVA ${ }^{1}$, KONSTANTIN BOGOLITSYN ${ }^{1,2}$, NIKOLAY LARIONOV ${ }^{1,2}$, TA- \\ TIANA BOYTSOVA ${ }^{1}$, IRINA PALAMARCHUK ${ }^{1}$, ANDREW AKSENOV ${ }^{1}$ \\ ${ }^{1}$ Institute of Ecological Problems of the North, Ural Division, Russian Academy of Sciences, Severnaya Dvina Emb. \\ 23, 163000, Arkhangelsk, Russia; e-mail: kia.iepn@gmail.com \\ ${ }^{2}$ Northern (Arctic) Federal University named after M.V. Lomonosov, Severnaya Dvina Emb. 17, 163002, Arkhan- \\ gelsk, Russia; e-mail: public@narfu.ru
}

\begin{abstract}
Kuznetsova I., Bogolitsyn K., Larionov N., Boytsova T., Palamarchuk I., Aksenov A.: Structure and physical-chemical properties of humic acids of oligotrophic peat bog of Arkhangelsk region. Ekológia (Bratislava), Vol. 33, No. 1, p. 1-8, 2014.

The article presents data on the elemental and functional composition of humic acids, their molecular weight characteristics, physical, chemical and acid-base properties. The sorption properties of humic acids towards $\mathrm{Cd}^{2+}$ and $\mathrm{Pb}^{2+}$ are studied. The relationship between the polyelectrolyte nature of humic acids and their sorption capacity is revealed.
\end{abstract}

Key words: humic acid, sorption, physico-chemical properties.

\section{Introduction}

Humic substances (HS) can be related to the most extensive and reacting class of natural compounds within the organic matter of soils, natural waters and solid fuels. Chemically, HS are a composition of humic (HA) and fulvic acids (FA) that differ by elemental composition, solubility and a range of molecular weights. HS are formed under natural conditions as a result of chemical and biological decomposition of plant and animal residues by microorganisms and abiotic environmental factors (Perminova, 2000). The basis of this process is the random sorting of kinetically stable structures and their integration into macromolecules. Ability of HS macromolecules to enter ionic and donor-acceptor interaction, as well as to form hydrogen bonds is determined by the presence of a wide range of oxygen-containing functional groups (such as carboxyl, phenolic and aliphatic hydroxyl, carbonyl, etc.), combined with the presence of aromatic fragments. Therefore, HS are actively involved in the migration of heavy metals by controlling their geochemical fluxes in the environment (Orlov, 1996; Linnik, 1986; Varshal, 1973, 1979). On the other hand, HS are self-assembled anionic polyfunctional polyelectrolytes (PEs), obtaining valuable colloid-chemical properties. 
One of the basic problems of the chemistry of polymer solutions is the estimation of relationships between structures and physico-chemical properties of macromolecules. Study of the properties of HS macroligands is an actual task, as HS play an important role in the processes of self-purification of water and soil ecosystems, binding of heavy metals and organic pollutants (Orlov, 1996; Misra et al., 2000).

Opposite geochemical role of the main HS components shows up in the process of complexation. FA refer to the soluble part of HS, increasing the migration ability of metals in the form of fulvic complexes. In contrast, $\mathrm{HA}$ are soluble only in alkaline solutions that do not exist in the environment. Thus, HA behave as complexing sorbents, accumulating and keeping the elements in soils, water suspensions and sediments.

It may be stated that the structural and functional characteristics of high-molecular compounds of organic matter of soils of Northern European Russia seem to be the least studied, according to literature survey.

Due to the fact that peat bogs are widely spread in Arkhangelsk region, north-west Russia (about $25 \%$ of peat of European part of Russia, $73 \%$ of which is present as oligotrophic peat bogs), study of HS as a raw material for extraction of variety of organic compounds, including the estimation of relationships between the composition, structure of HS and their reactivity, should be performed.

Arkhangelsk region is located in the north-western part of Russia (Fig. 1). The climate is Arctic (islands and Nenets region and north-eastern part of the region) and Subarctic (the rest area). Landscapes are cold desert and boreal zones. The main soil types in the region are podzol, gley-podzol soils, peats. Wetlands are mainly located in the northern part of the region and along the Onega River basin (up to 25\%) due to the valley type of the territory, slow drainage and presence of the clay layers. Severnaya Dvina River basin's bogginess is $8.5 \%$.

The aim of this paper is to study the correlation between sorption presented by HA, isolated from the peat of the Arkhangelsk region, and the structural and functional features of HA.

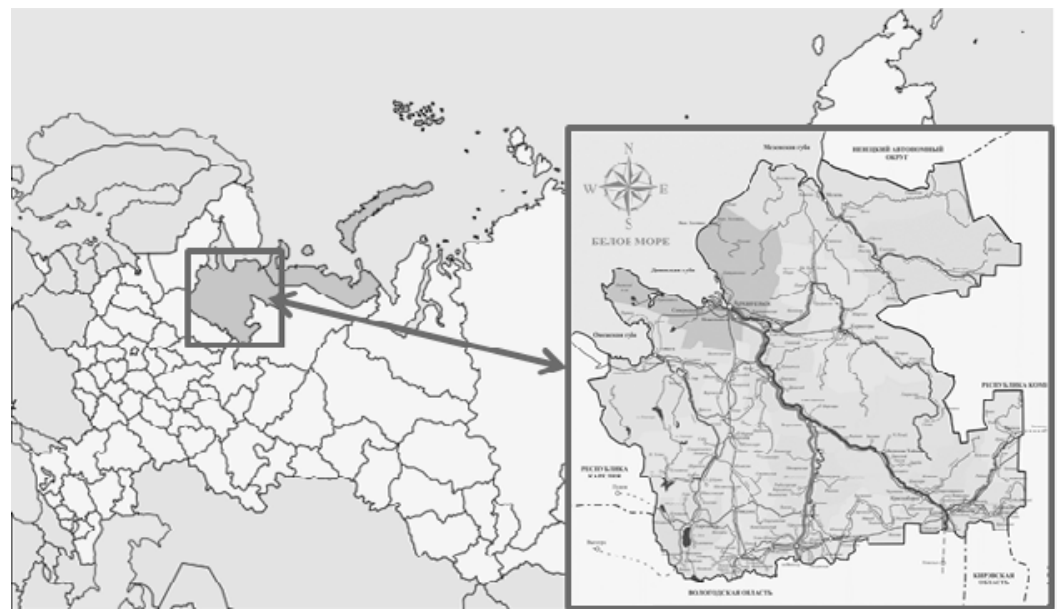

Fig. 1. Location of Arkhangelsk region. 


\section{Material and methods}

HA were extracted from oligotrophic (upland) bog, located in Arkhangelsk region (north-west Russia), in accordance with Orlov et al. (2005). HS were extracted by adding $0.1 \mathrm{~N} \mathrm{NaOH}$ to the air-dry peat sample. The supernatant solution, after separation, was acidified to $\mathrm{pH}=2$ with $\mathrm{HCl}$. Then coagulated $\mathrm{HA}$ were centrifuged. $\mathrm{HA}$ were dried at $40^{\circ} \mathrm{C}$ temperature.

Potentiometric, viscosity and surface tension properties were studied by dissolving weighed HA sample in a small amount of $0.1 \mathrm{~N} \mathrm{NaOH}$, then the solution was adjusted to $\mathrm{pH}=7$ with distilled water.

Total amount of acid, hydroxyl, carboxyl and methoxyl groups in HA samples was determined by chemisorption methods (Zakhis, 1987; Klimova, 1975). Content of carbon, hydrogen, oxygen and nitrogen in HA samples was studied using analyser Elementar Vario Micro CUBE.

Weight-average molecular weights $\left(M_{w}\right)$ and number-average molecular weights $\left(M_{n}\right)$ of HA were determined by gel permeation chromatography (GPC) using analyser Gibson Abimed. Molecular-mass characteristics of commercial HA sample (Aldrich), obtained from leonardite, were compared to those of selected HA. Polydispersity (D) was expressed through the ratio of both averaged molecular weights, $D=M_{w} / M_{n}$.

Viscometric measurements of polymer solutions and their complexes were carried out using Ostwald viscometer with $0.36 \mathrm{~mm}$ capillary diameter at a temperature of $25.0 \pm 0.1^{\circ} \mathrm{C}$. Passage time between two etched marks from the upper to lower end was checked no less than five times for each concentration and all passage times with $<0.3 \mathrm{~s}$ difference.

Potentiometric measurements were performed using Hanna instruments $\mathrm{pH}$ meter 211 with pH electrode combination HI 1131B.HA were added to the known volume of distilled water, then $\mathrm{pH}$ was adjusted to $11-12$ with $1 \mathrm{~N} \mathrm{NaOH}$ in order to titrate sample.

The surface tension studies were carried out using tensiometric method at a temperature of $25.0 \pm 0.1{ }^{\circ} \mathrm{C}$. The confidence interval for the surface tension is $\pm 0.2 \times 10^{-3} \mathrm{~J} / \mathrm{m}^{2}$.

Sorption of $\mathrm{Cd}^{2+}$ and $\mathrm{Pb}^{2+}$ ions was performed in a static mode at a sorbent:solution ratio of 1:200 and $\mathrm{pH}=3$. Ions concentration in model solutions varied between 10 and $1000 \mathrm{mg} / \mathrm{l}$ for $\mathrm{Cd}^{2+}$ and 9 and $900 \mathrm{mg} / \mathrm{l}$ for $\mathrm{Pb}^{2+}$. Equilibrium concentration of $\mathrm{Cd}^{2+}$ and $\mathrm{Pb}^{2+}$ in solution was studied by atomic absorption method using a spectrometer novAA 315 (Analytik Jena AG).

\section{Results and discussion}

\section{Structure of humic substances, based on the study of the elemental and functional composition}

The basic composition and atomic ratios of the studied samples are listed in Table 1. The atomic ratio $\mathrm{H} / \mathrm{C}$ and $\mathrm{O} / \mathrm{C}$ displays a polymer structure, as well as the content of unsaturated fragments and oxygen-containing functional groups. In selected samples, the value of H/C (1.09) suggests that the structure of humic acids is equally represented by both aromatic and aliphatic fragments with a linear structure (Ephraim et al., 1989).

Quantitative characteristic of the content of basic functional groups is needed to explain and predict the chemical behaviour of the HA and their reactivity towards polar and ionic compounds.

The results show that HA, containing aromatic and aliphatic fragments, have a high content of functional groups (Table 1).

$\mathrm{T}$ a b l e 1. Basic and functional composition (\% weight on an ash-free basis) and atomic ratios of the HA.

\begin{tabular}{|c|c|c|c|c|c|c|c|c|c|}
\hline \multirow{2}{*}{ Sample } & \multicolumn{4}{|c|}{ Basic composition } & Atomic ratio & \multicolumn{3}{c|}{ Functional composition } \\
\cline { 2 - 10 } & $\mathrm{N} \pm \Delta$ & $\mathrm{C} \pm \Delta$ & $\mathrm{H} \pm \Delta$ & $\mathrm{O} \pm \Delta$ & $\mathrm{H} / \mathrm{C}$ & $\mathrm{O} / \mathrm{C}$ & $-\mathrm{COOH}+-\mathrm{OH}$ & $-\mathrm{COOH}$ & $-\mathrm{OH}$ \\
\hline $\mathrm{HA}$ & $2.3 \pm 0.2$ & $51.5 \pm 3.9$ & $4.7 \pm 0.2$ & $39.4 \pm 0.2$ & 1.09 & 0.57 & $13.17 \pm 1.10$ & $4.81 \pm 0.40$ & $8.36 \pm 0.83$ \\
\hline
\end{tabular}


Molecular weight is one of the most important characteristics of HA that determine their behaviour in solutions, the ability to migrate in the environment and interaction with enzyme systems. The most common method of its determination is by gel permeation chromatography, helping to obtain information about the full curve of molecular weight distribution. Table 2 shows molecular mass properties of the samples (number-average molar mass $\left[M_{n}\right]$ and weight-average molar mass $\left[\mathrm{M}_{\mathrm{w}}\right]$ ) obtained by gel permeation chromatography method.

T a b l e 2. Molecular mass characteristics of HS.

\begin{tabular}{|c|c|c|c|}
\hline Sample & $\mathrm{M}_{w^{\prime}}, \mathrm{KDa}$ & $\mathrm{M}_{\mathrm{n}}, \mathrm{KDa}$ & $\mathrm{M}_{\mathrm{w}} / \mathrm{M}_{\mathrm{n}}$ \\
\hline HA & 36.7 & 5.4 & 6.9 \\
\hline HA-AL & 13.6 & 3.3 & 4.1 \\
\hline
\end{tabular}

For HA, the polydispersity is confirmed by bimodal molecular weight distribution obtained by GPC and a high degree of polydispersity value (6.9). For the commercial sample HA-AL, the obtained dependence has monomodal character. Obtained data are in accordance with the research data, published earlier Conte and Piccolo (1999a).

\section{Conformational changes in the molecules of humic substances}

Being high-molecular ionic compound, HA represent polyelectrolyte properties (Perminova, 2000; Ivanov et al., 2008). Macromolecular electrolytes are notable for concentration anomaly of the reduced viscosity arising from the polyelectrolyte effect: viscosity is increasing at the dilution of PE solutions. Anomaly differentiates electrolytes from uncharged polymers in solutions and occurs due to conformational changes of PE: decrease of the concentration of the aqueous solutions of PE leads to unfolding of macromolecular coils, as a result of electrostatic repulsion of likely charged groups, as well as to the increase of their size, resulting in an increase of the reduced viscosity ( $\eta$ ) of the solutions (Fig. 2).

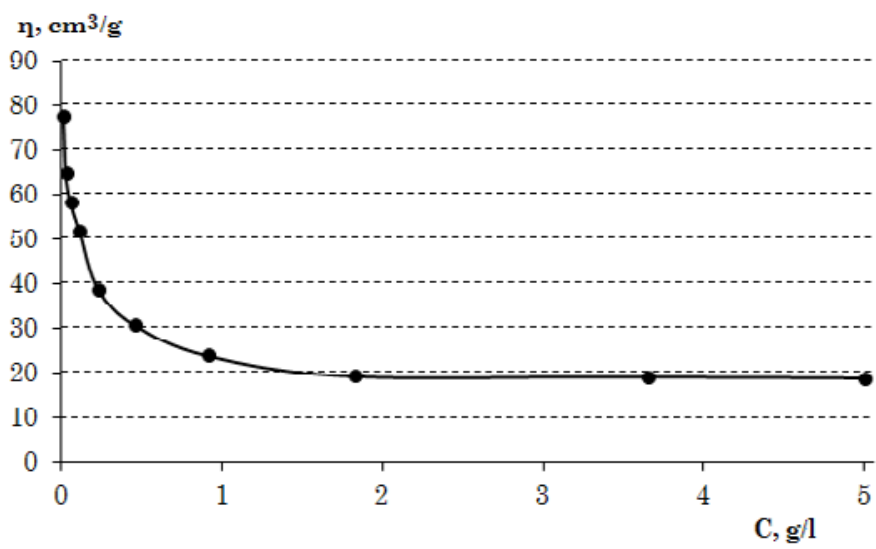

Fig. 2. Concentration dependence of the reduced viscosity $\mathrm{HA}(\mathrm{pH}=7.1)$. 


\section{Potentiometric titrations}

The results of potentiometric titration suggest that the structure of HA has two types of acidic groups, which differ by strength. Two end-points are available on the titration curve within the slightly alkaline and slightly acid medium, confirming the presence of functional groups $(-\mathrm{COOH}$ and $-\mathrm{OH})$ of a different nature and reactivity. The dissociation of carboxyl and phenolic hydroxyl groups within HA-Na is characterized by pK 4.4 and 9.2, respectively. Normally, $\mathrm{pH}=7.0$ is considered to be the end of the titration of carboxyl groups, and $\mathrm{pH}=$ 10.2-10.3, the end of titration of all acid groups (Ephraim et al., 1989). Obviously, such method of determination of the carboxyl groups is rather uncertain, since $\mathrm{pH}$ at the end titration point for many organic acids is higher than 7 (Skoog et al., 1979), and that for weak phenolic hydroxide is higher than 11 . The HA acidity is determined by the content of carboxyl and phenolic hydroxyl groups, and their total content is $5.98 \pm 0.68 \%$.

\section{Surface-active properties}

Surface-active properties of the HS are determined by the presence of both hydrophobic and hydrophilic fragments in their structure. It is known that the HA salts show low surface activity at the 'liquid-gas' phase boundary (Hilko et al., 2006). The boundary tension isotherms of the slightly alkaline HA solutions were obtained by Wilhelmy method (Fig. 3). The surface tension decreases monotonically with the increase of concentration, and then changes dramatically under the critical concentration - its value remains stable. Critical micelle concentration (CMC) was stated by fixing the change of conductivity of the solutions of sodium humate, and according to the inflection point of the curve $\sigma=f(C)$.

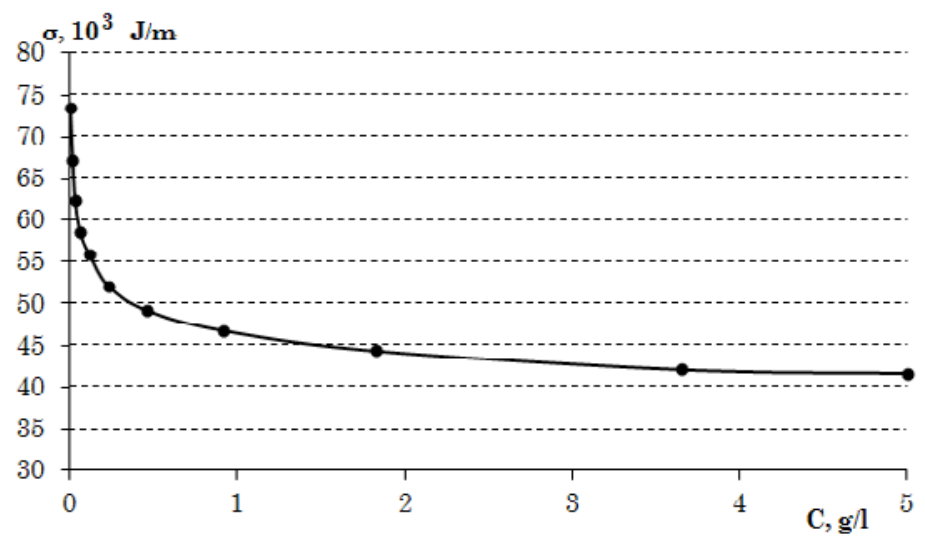

Fig. 3. Dependence of the surface tension of the HA on its concentration.

Amphiphilic character of HA structure contributes to the formation of supramolecular aggregates - micelles, due to the association of relatively small heterogeneous macromolecules caused by the weak van der Waals interactions. Micelles do not possess surface activity and do not cause further reduction of the surface tension of the solvent at the interface. 
HA contain a large number of functional groups that can ionize. Therefore, they may form stable complexes with the heavy metals cations. Binding of heavy metals by HA occurs mainly due to complexation through coordination of HA-metal bonds (Kulikova, 2008).

Coordination occurs through the oxygen atom of the HA donor group (methoxyl, carboxyl, phenolic). Ion exchange takes place through hydrogen ions of oxygen-containing functional groups. Acidic and polyelectrolytic properties determine reactivity of HA, ultimately affecting migration of heavy metals, radionuclides, organic pollutants and thus controlling their geochemical fluxes.

Explanation of the mechanism of sorption of heavy metals by HA requires preliminary assessment of their sorption capacity and kinetics by obtaining the equilibrium sorption isotherms. It is established experimentally that equilibrium is reached in the first $10 \mathrm{~min}$ utes of contact between the solid and liquid phase. The obtained data were further used to plan the experiment.

The calculation of the HA binding activity towards $\mathrm{Cd}^{2+}$ and $\mathrm{Pb}^{2+}$ was performed using Freundlich and Langmuir equations (the theory of monomolecular adsorption), which are commonly used to evaluate the sorption capacity of fibrous materials, as well as using the equation of Brunauer, Emmett and Teller (the so-called BET theory), which describes the multilayer adsorption. Different equations for data processing were chosen due to the heterogeneity of HA sorption centers, as well as the nature of the sorption isotherms (Minkina et al., 2005).

As shown above, the dissociation of carboxyl and phenolic hydroxyl groups is characterized by $\mathrm{pK}=3.5-4.0$ and 8.5-9.0, respectively (Fig. 3). Consequently, the sorption isotherm can hardly be alike over the entire range of saturation of HA groups by metal ions. Naturally, a superposition of the curves, characterizing the binding of the metal ions by the different functional groups, may take place. Established sorption capacity and the coefficients of the equations are presented in Table 3.

T a b l e 3. Binding of $\mathrm{Cd}^{2+}$ and $\mathrm{Pb}^{2+}$ by HA under $\mathrm{T}=296 \mathrm{~K}$.

\begin{tabular}{|l|c|c|c|c|c|c|}
\hline \multirow{2}{*}{ Metal ion } & \multicolumn{2}{|c|}{ Langmuir equation } & \multicolumn{2}{c|}{ Freundlich equation } & \multicolumn{2}{c|}{ BET equation } \\
\cline { 2 - 7 } & $\mathrm{G}_{\infty}, \mathrm{mg} / \mathrm{g}$ & $\mathrm{k}$ & $\beta, \mathrm{mg} / \mathrm{g}$ & $\mathrm{N}$ & $\mathrm{Am}, \mathrm{mg} / \mathrm{g}$ & $\mathrm{k}$ \\
\hline $\mathrm{Pb}^{2+}$ & 89.3 & 0.03 & 4.99 & 0.44 & 54.4 & 31.6 \\
\hline $\mathrm{Cd}^{2+}$ & 20.6 & 0.41 & 3.60 & 0.42 & 23.4 & 21.4 \\
\hline
\end{tabular}

As is shown in Tables 2 and 3, the amount of carboxyl groups correlates with the metal cation binding, calculated according to Langmuir equation $\left(\mathrm{R}^{2}=0.463\right.$ - moderate correlation) and according to BET theory $\left(\mathrm{R}^{2}=0.997\right.$ - a significant correlation).

Sorption capacity depends considerably on the ionic radius and charge density. Higher sorption capacity shows ions of a larger radius, as they are more polarized and more attracted to the charged surface of the sorbent, while the ions of smaller radius are more 
prone to the formation of hydration shell, which reduces this electrostatic interaction. The radius of the cadmium ion is $0.099 \mathrm{~nm}$, while the ionic radius of lead is $0.126 \mathrm{~nm}$. Therefore, the binding of lead ions should be higher than that of cadmium ions.

Thus, the quantitative characteristics of the binding of heavy metal ions by HA characterize the latter as highly active natural sorbents, and identify the possibility of utilization of HA as a purifying material for the removal of heavy metals.

\section{Conclusion}

It is shown that the sorption and complexing properties of macromolecules in solution are determined by the structural features of HA (irregularity, presence of condensed aromatic structures, fragments with a linear structure) and the presence of a significant number of macromolecules of different nature and the strength of functional groups $(-\mathrm{COOH}$ and $-\mathrm{OH})$. Based on the sorption rate, the basic possibility of using humic and fulvic acids, isolated from the peat, as sorbents of heavy metals is stated.

2. Systematical studies of the properties of the humic substances, isolated from the oligotrophic peats of Arkhangelsk region, are determined by the considerable areas of the wetlands within the region, and, furthermore, by the ability to create cheap and effective functional polymer materials of various applications on their basis.

\section{Acknowledgements}

The work is supported by the Federal Program 'Scientific and Scientific-Pedagogical Personnel of the Innovative Russia' for 2009-2013 (SC № 16.740.11.0159).

The authors would like to express their gratitude to Dr. Irina Perminova and her colleagues from Moscow State University, named after M.V. Lomonosov, for studies on molecular mass properties of the samples, as well as to Dr. Andrey Khudoshin for performing C-, H-, N-analyses.

\section{References}

Belitsina, G.D., Vasilevskaya, V.D. \& Grishina L.A. (1988). Soil and pedogenesis. Moscow: High School.

Conte, P. \& Piccolo A. (1999). High pressure size exclusion chromatography (HPSEC) of humic substances. Molecular sizes, analytical parameters, and columns performance. Chemosphere, 38, 517-528. DOI: 10.1016/ S0045-6535(98)00198-2.

Ephraim, J.H., Boren, H., Arsenie, I., Pettersons, C. \& Allard B.A. (1989). Combination of acid - base titrations and derivatization for functional group determinations of an aquatic fulvic acid. Science of the Total Environment, 81, 615-624. DOI: 10.1016/0048-9697(89)90170-8.

Hilko, S.L. \& Titov E.V. (2006). Physico-chemical properties of humic acid salts. Solid Fuel Chemistry, 3, $12-23$.

Klimova, V.A. (1975). Basic micromethods of organic compounds analysis. Moscow: Chemistry.

Kulikova, N.A. (2008): The protective effect of humic substances to plants in soil and water environments in terms of abiotic stresses. Moscow: Publishing House of Moscow State University.

Ladd, J.N. \& Butler J.H. (1975). Humus-enzyme systems and synthetic organic polymer-enzyme analogs. In E.A. Paul \& A.D. McLaren (Eds.), Soil Biochemistry, vol. 4 (pp. 143-194). New York: Marcel Dekker.

Linnik, P.N. (1986). Forms of migration of metals in fresh surface waters. Leningrad: Gidrometeoizdat.

Minkina, T.M., Pinsky, J.L., Samokhin, A.P. \& Statovoy A.A. (2005): The absorption of copper, zinc and lead an ordinary chernozem at monoelementnom and polyelement pollution. Agricultural Chemistry, 8, 58-64.

Misra, V., Pandey, S.D. \& Viswanathan P.N. (2000): Effect of humic acid on the bioavailability of $\gamma$-hexachlorocyclohexane in Marsilea minuta (L.). Environmental Monitoring and Assessment, 61, $231-237$. DOI: 10.1023/A:1006171206492. 
Orlov, D.S. (1985). Chemistry of soil. Moscow: Publishing House of Moscow State University.

Orlov, D.S. (1996). Chemistry and soil protection. Soros Educational Journal, 3, 67-74.

Orlov, D.S., Sadovnikova, L.K. \& Sukhanov N.I. (2005). Chemistry of soils. Moscow: High School.

Perminova, I.V. (2000). Analysis, classification and prediction of properties of humic acids. Doctoral thesis, Moscow.

Rostovschikova, I.N., Korneeva, G.A. \& Stepanova, A.A. (1999): The enzymatic degradation of natural humic substances. Bulletin of Moscow State University, Ser. 17, 4, 22-27.

Rice, J.A. \& McCarthy P. (1991). Statistical evaluation of the elemental composition of humic substances. Organic Geochemistry, 17(5), 635-648. DOI: 10.1016/0146-6380(91)90006-6.

Skoog, D.A. \& West D. (1979). Fundamentals of Analytical Chemistry. Moscow: Mir.

Tulskaya, E.M. (1981). Localization and specificity of action of catalase in the soil. Doctoral thesis, Moscow.

Varshal, G.M. (1973). Fractionation, quantification, and study some of the major components of dissolved organic matter in natural waters. Hydrochemical Materials, 59, 143-151.

Varshal, G.M. (1979). On the relationship between the sorption capacity of the carbonaceous matter of rocks in relation to the noble metals in its structure. Geochemistry, 4, 598-607.

Verezhnikov, V.N. (1984). Workshop on colloid chemistry of surfactants. Voronezh: Publishing House of Voronezh University.

Zakis, G.F. (1987). Functional analysis of lignins and their derivatives. Riga: Zinatne.

Zvyagintseva, D.G. (1986). The ecological role of microbial metabolites. Moscow: Publisher of Moscow State University. 